\title{
Review
}

Journal of Innate

Immunity
J Innate Immun 2011;3:9-16

DOI: $\underline{10.1159 / 000321005}$
Received: August 12, 2010

Accepted after revision: September 2, 2010

Published online: October 28, 2010

\section{Coagulation in Vertebrates with a Focus on Evolution and Inflammation}

\author{
Russell F. Doolittle \\ Departments of Chemistry and Biochemistry and Molecular Biology, University of California, San Diego, \\ La Jolla, Calif., USA
}

\section{Key Words}

Evolution · Clotting · Inflammation · Protochordates •

Vertebrates $\cdot$ Contact phase

\begin{abstract}
The evolution of a thrombin-generating system that produces a gelatinous clot to prevent the loss of blood occurred in parallel with the evolution of inflammatory responses that depend on bradykinin generation. Bioinformatics approaches that inventory the presence or absence of genes involved in these two processes support the view that both became progressively more complex during the period between the divergence of jawless fish and the appearance of mammals. Although the roots of both systems may extend to protochordates, they arose quite independently.
\end{abstract}

Copyright $\odot 2010$ S. Karger AG, Basel

\section{Introduction}

In line with the theme of this special issue of the Journal of Innate Immunology, this review was invited to address matters of coagulation in vertebrates with a focus on evolutionary aspects and inflammation. Associations between clotting and various inflammatory responses have long been recognized, including aspects dealing with injury, infections and systemic diseases [1-3]. Here, we limit ourselves to a few well-defined points of macromolecular articulation, particularly emphasizing how natural selection has coupled the production of kinins, on the one hand, to the generation of thrombin-catalyzed fibrin formation, on the other.

In this regard, it is a longstanding observation that mammalian blood plasma develops the ability to induce pain and increase vascular permeability following its exposure to glass surfaces [4]. The connection to the blood clotting pathway was immediately evident when it was shown that under the same conditions plasma deficient in factor XII (Hageman factor) did not give rise to those responses [5]. The pain and permeability response was mainly the result of the release of kinins - especially bradykinin and kallidin - small peptides that bind to receptors on a wide variety of cells and that provoke diverse inflammatory responses.

In mammals, the principal source of these kinins is high molecular weight kininogen (HMWK), and their release is due to the releasing action of $\alpha$-kallikrein, itself the product of limited proteolysis reciprocally enacted by factor XIIa on its precursor, prekallikrein, in the presence of HMWK (fig. 1). The response is greatly stimulated by contact with alien surfaces, be it glass or kaolin, some infectious particle or other foreign material.

\section{KARGER}

Fax +4161306 1234

E-Mail karger@karger.ch

www.karger.com
(C) 2010 S. Karger AG, Basel

1662-811X/11/0031-0009\$38.00/0

Accessible online at:

www.karger.com/jin
Dr. Russell F. Doolittle

Department of Chemistry and Biochemistry

University of California, San Diego

La Jolla, CA 92093-0314 (USA)

Tel. +1 858534 4417, Fax +1 858534 4985, E-Mail rdoolittle@ucsd.edu 
Fig. 1. Schematic depiction of where blood clotting and inflammation responses meet (adapted from Oehmcke and Herwald [3]).



Table 1. Phyletic occurrence of contact phase components

\begin{tabular}{|c|c|c|c|c|c|c|c|}
\hline Organism & $\begin{array}{l}\text { Factor } \\
\text { XI }\end{array}$ & $\begin{array}{l}\text { Prekal- } \\
\text { likrein }\end{array}$ & $\begin{array}{l}\text { Factor } \\
\text { XII }\end{array}$ & $\begin{array}{l}\text { Kininogen } \\
\text { cystatin }\end{array}$ & $\begin{array}{l}\text { Kininogen } \\
\text { bradykinin }\end{array}$ & $\begin{array}{l}\text { Kininogen } \\
\text { His-rich }\end{array}$ & $\begin{array}{l}\text { Kininogen } \\
\text { association }\end{array}$ \\
\hline Human & yes & yes & yes & 3 & 1 & 1 & 1 \\
\hline Opossum & yes & yes & yes & 3 & 1 & 1 & 1 \\
\hline Platypus & no & yes & yes & 3 & 1 & 1 & 1 \\
\hline Chicken & no & yes & no & 3 & 1 & 1 & 1 \\
\hline Lizard & no & yes & yes & 3 & 1 & 1 & 1 \\
\hline Zebrafish & no & no & no & 2 & 1 & 0 & 0 \\
\hline Pufferfish & no & no & no & 2 & 1 & 0 & 0 \\
\hline Lamprey & no & no & no & 1 & 1 & 0 & 0 \\
\hline
\end{tabular}

'Yes' and 'no' denote presence or absence of contact factor proteases as reported in Ponczec et al. [7]. Numbers in kininogen columns indicate numbers of each kind of domain present in an organism's protein as reported by Zhou and colleagues [15, 16]. Lizard data are unpublished observations by the author.

But factor XIIa also cleaves factor XI, converting it to an active protease that activates factor IX, thereby initiating an involvement with what has traditionally been called the intrinsic clotting pathway. If there had been any doubt about the linkage between the two systems, this was wholly dispelled by the demonstration that polyphosphates mediate both processes in vivo [6].

\section{Parallel Evolution of Kininogens and Contact Factor Proteases}

We begin our discussion of how these two responses have come together during the course of evolution by noting that of the five interacting gene products depicted in figure 1, four do not occur in jawless fish, and the fifth,
HMWK, is greatly simplified in those creatures. The first task is to establish when these particular genes made their appearance, or were modified, in a phylogenetic sense. Our tactic will be to work backwards in time, looking to account for clotting and kinin-kininogen components known to occur in extant mammals.

The strategy greatly depends on computer searching through whole genome sequences of representative animals, the rationale being that genes for known components of various processes will be present or not, due care being taken to distinguish orthologs from paralogs. It is especially important that 'hits', no matter how strong a resemblance between query and found, be confirmed by back-searching against GenBank before declaring orthology. Conserved synteny (chromosomal gene arrangement) can also be used for validation and, 
whenever possible, phylogenetic trees should be constructed.

In the case of vertebrate clotting, the assumption has been that the well-studied pathways of mammals provide a starting inventory of genes for searching. Although there may be still unidentified factors in some nonmammalian lineages, it is already apparent that nonmammals lack some of the genes for what is generally accepted as the standard set.

As an example, publication of the whole genome sequence of the duck-billed platypus, a monotreme sometimes called an 'egg-laying mammal,' revealed that these creatures lack coagulation factor XI [7]. In contrast, the genome of the opossum, a genuine marsupial that evolved later, has a factor XI gene adjacent to a prekallikrein gene, as would be expected for a recent duplication. Evidence favoring the predecessor of this gene duplication being a gene for prekallikrein and not factor XI has been presented [7]. By those criteria, no gene for factor XI has been found in any nonmammal.

Because the contact factor system was long ago reported to be absent from birds [8-10], it was not surprising to find that, besides not having factor XI, the chicken genome does not have a gene for factor XII [7]. On the other hand, a factor XII gene is present in the genome of a reptile, the Carolina green lizard [11], and frogs [7], suggesting that birds have lost the gene for factor XII, as opposed to never having had it. It is well known that some marine mammals (cetaceans) have also lost a functional gene for factor XII [12].

Fish with jaws do not have any of the three contact factor proteases (prekallikrein, factors XI and XII) [13]; jawless fish like the lamprey lack these three and also factor IX [14], which in mammals is the primary target for factor XIa.

As for HMWK, a comprehensive study $[15,16]$ has shown that the gene for this protein has engaged in a series of domain shuffles during evolution, the complexity of the final product evolving more or less in parallel with the appearances of the three contact proteases. Lampreys have the simplest kininogen, being composed of only a single cystatin domain and a bradykinin domain [16], the latter naturally being the source of the kinin. Bony fish like puffer fish and zebra fish have kininogens with an additional cystatin domain [15].

Birds and mammals have kininogens that are much more complex (fig. 2), being composed of three cystatin domains, a bradykinin domain, a histidine-rich domain and a carboxyl-terminal domain that in mammals is known to bind both prekallikrein and its recent paralog,

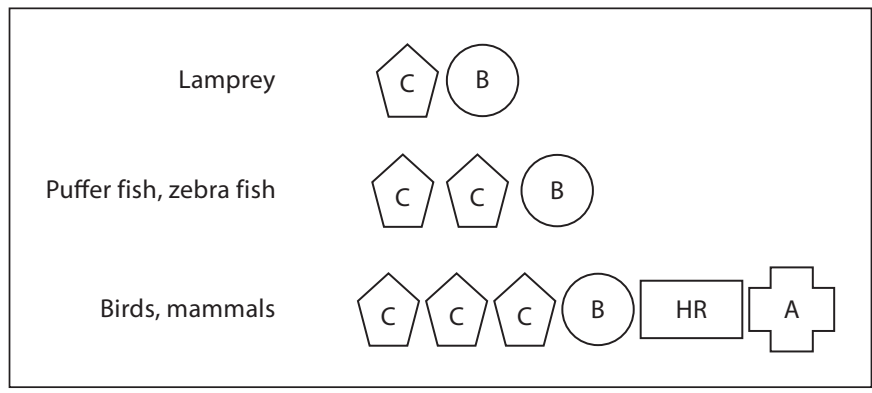

Fig. 2. Domain combinations in vertebrate kininogens. $\mathrm{C}=$ Cystatin domain; $\mathrm{B}=$ bradykinin domain, $+++=$ histidine-rich domain; $\mathrm{A}=$ association domain for binding prekallikrein and/or factor XI (adapted from Zhou et al. [15, 16]).

factor XI [15]. The histidine-rich domain lies at the heart of factor XII contact activation.

The picture that emerges suggests that the inflammatory response initiated by kinins evolved independently of events leading to fibrin formation, the two pathways coming together after the appearance of tetrapods (table 1). The situation in amphibians is murkier because these creatures have transformed the kininogen-kinin system into a protective device exclusively associated with skin [15].

The parallel progression of the two processes - clotting and kinin formation - by gene duplication in the case of the former and domain acquisition and shuffling in the latter, seems altogether reasonable, although some aspects of the situation beg for laboratory verification. It is not clear, for example, what protease cleaves kinins from kininogen in fish, given that a typical prekallikrein gene is absent. It is well established that bradykinin occurs in fish plasma and is released from a precursor kininogen by exogenous kallikreins isolated from mammalian pancreas [17]. It has also been reported that a pair of tandemly arranged bradykinin receptors are present in bony fish in the same way they are in birds and mammals [18]. What remains unclear is what endogenous protease in fish releases bradykinin, given the absence of genes for contact factor proteases.

The answer may lie in the realization that a period of 'cross-talk' must ensue after any gene duplication involving a protease or its target, and a degree of redundant activity is likely to endure even as diversification ensues. For example, in bony fish the activation of factor IX, in the absence of a gene for factor XII, is likely accomplished by factor VIIa, just as in mammals where factor VIIa plays a secondary role in activating factor IX, even in the 
presence of factor XI [19]. In the case of the kininogens, the activating protease might be a tissue kallikrein. The question cries out for experiment.

\section{Clotting and Inflammation in Jawless Fish}

Evidence continues to accumulate that both the clotting and inflammatory response pathways are less complex in jawless fish than they are in bony fish. Besides lacking genes for the contact factor proteases, current assemblies of the lamprey genome also lack genes for factors VIII and IX [14]. Moreover, persistent efforts to clone these factors from lampreys have failed [20]. In another example of the simpler scheme that exists in lampreys, the serpin antithrombin III appears to be absent. No gene for this protein can be found, either by searching current versions of the genome database or by cloning [21]. On the other hand, a gene for heparin cofactor II, a related serpin, is present [21].

With regard to kinins and kininogens, we have already remarked on the simpler kininogen structure in lampreys [16]. It has also been shown that in hagfish, bradykinin promotes vasorelaxation of precontracted mesenteric arteries [22], and by inference the kinin-kininogen system must be a part of that creature's physiology, too.

In lampreys there appears to be only a single bradykinin receptor located on supercontig 15747 in the current assembly, and not a tandemly arranged pair as occurs in bony fish and other vertebrates (unpublished observation by the author). Apparently, the gene duplication that gave rise to the tandem pair had not yet occurred when the jawless fish lineage diverged. As it happens, the next closest match to the receptor in the database is an angiotensin II receptor (supercontig 23119). The presence of an angiotensinogen system in lampreys has been documented both by direct experiment [23] and by cloning [21]. Both of these receptors, bradykinin and angiotensin II, belong to the vast family of 7-membrane spanner proteins ( $G$ protein-associated proteins), a group that has been shown to be relatively underrepresented in lampreys compared with bony fish [24].

In passing, it might be noted that lamprey lacks several complement genes [20]. Complement factor C3 (anaphylotoxin) is present, but the closely related complement factors C4 and C5 are not. Similarly, although there are several mannose-binding lectin-associated serine proteases in lampreys, the paralogous complement components C1r and C1s are absent [25].

\section{Looking for Roots among the Protochordates}

The determination of whole genome sequences from two protochordates has brought welcome attention to these vertebrate forebears, although much important biology and biochemistry preceded those sequences. One of the whole genomes completed was for the sea squirt, Ciona intestinales [26], the other was for amphioxus, Branchiostoma floridae [27]. C. intestinales is a tunicate, also known as an ascidian, and belongs to the group denoted urochordates. B. floridae, sometimes called the lancelet, is a cephalochordate.

Until the completion of these two genomes there was disagreement as to which was the basal chordate and which the nearer relative of vertebrates. Current consensus is that $B$. floridae is basal (earlier diverging) and $C$. intestinales is the nearer relative of vertebrates. Consistent with this view, amphioxus does not have any kind of blood clotting, nor does it have circulating cells of any type in its hemolymph. In contrast, ascidians are well known for having circulating cells, hemocytes, that aggregate at the site of wounds [28], and it has been reported that Met-Lys-bradykinin brings about their aggregation in the ascidian, Halocynthis roretzi [29].

Although there is general agreement that extracellular clots do not occur in tunicates [28], there is a longstanding report of thrombin being present in the hemolymph of $H$. roretzi [30]. The question arises whether this enzyme, which is able to convert bovine fibrinogen into fibrin, is a genuine ortholog of vertebrate prothrombin or an enzyme with a different function in tunicates that happens to be able to cleave the fibrinopeptides from mammalian fibrinogen. A convincing proof for orthology would need demonstration of an amino acid sequence that resembles vertebrate thrombins more than it does other serine proteases.

Both protochordate genomes have been intensively searched for genes that might encode clotting factors, as well as for many involved in inflammation. Initially it was concluded that no bona fide clotting factors exist in the $C$. intestinales genome, although the various protein domains of which vertebrate clotting factors are composed are mostly present, including the relatively rare GLA domain that typifies vitamin K-dependent factors in vertebrates [13].

None of the GLA domains found in C. intestinales were associated with proteases, although they invariably occurred in tandem with EGF domains [13], another domain commonly observed in coagulation proteases. Cloning studies have confirmed that none of these occur 
Fig. 3. Comparison of ferroxidase-containing (denoted by A1-A3) proteins from human, amphioxus (B. floridae) and sea squirt (C. intestinales). Discoidin domains are denoted $\mathrm{C}$; the long, nondescript middle regions that occur in human factors $\mathrm{V}$ and VIII are denoted B. MS = Membrane spanner.

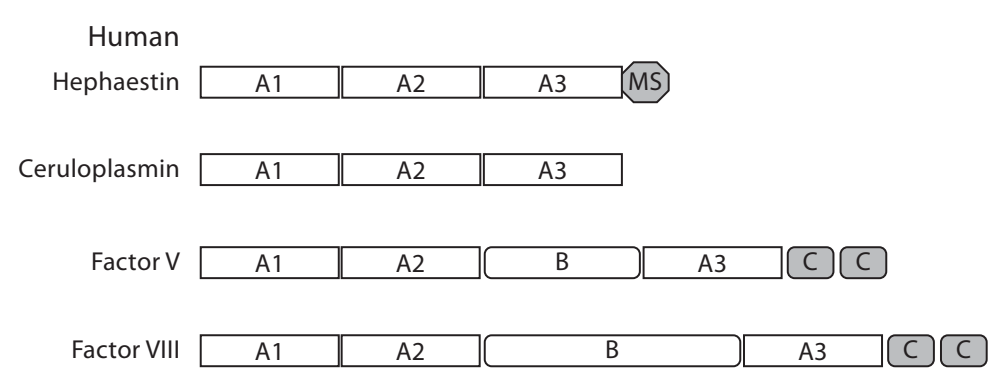

Amphioxus

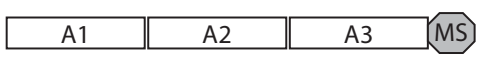

\begin{tabular}{|l||l||l|}
$\mathrm{A} 1$ & $\mathrm{~A} 2$ & $\mathrm{~A} 3$ \\
\hline
\end{tabular}

Sea squirt

\begin{tabular}{|l|l|l|l|}
\hline $\mathrm{A} 1$ & $\mathrm{~A} 2$ & $\mathrm{~A} 3$ & $\mathrm{MS}$ \\
\hline
\end{tabular}

\begin{tabular}{l||l||l|l|l|l}
$\mathrm{A} 1$ & $\mathrm{~A} 2$ & $\mathrm{~A} 3$ & $\mathrm{C}$ & $\mathrm{C}$ \\
\hline
\end{tabular} with a protease domain; instead they are accompanied by 2-17 EGF domains [31]. Of more than passing interest was a protein among these with seventeen EGF domains followed by two laminin $G$ domains. Intriguingly, the vertebrate clotting factor protein S has a GLA domain followed by four EGF domains and two laminin $\mathrm{G}$ domains. This remarkable coincidence is compounded by the observation that, like protein $S$, the sea squirt protein has a distinctive disulfide loop adjacent to the GLA domain [31]. Not all GLA domains in tunicates are in the exclusive company of EGF domains, however, one in $H$. roretzi was found attached to a receptor kinase [32].

Other domains found in vertebrate clotting proteins have also been searched for in the protochordate genomes, including kringles and discoidin domains. Kringles have been found to be peripheral to serine proteases in C. intestinales, just as they occur in vertebrate plasminogen and hepatocyte growth factor [13].

Computer searching of the $C$. intestinales genome also uncovered a protein that looks suspiciously like a predecessor of factor V or VIII in that it has three ferroxidase A domains of the sort found in ceruloplasmin and hephaestin, as well as two discoidin domains, just as is the case in vertebrate factors V and VIII (fig. 3). Originally, this gene was identified on scaffold 87 of the draft assembly; its current GenBank identification number is XP_002122537.
Another gene for a ferroxidase protein is also present in the $C$. intestinales genome, but this one appears to be an ortholog of haphaestin, the intestinal iron transport protein, in that it has a membrane-spanning segment of the sort that in vertebrates anchors it to the gut wall (GenBank identification number XP_002119762.1). The membrane spanner is what distinguishes hephaestin from its close relative ceruloplasmin.

Interestingly, the amphioxus genome also has two ferroxidase-containing genes, one like hephaestin with a characteristic membrane-spanner near its carboxyl terminus (GenBank identification number XP_002593057) and the other with a sequence that has an equally strong resemblance to vertebrate ceruloplasmin (GenBank identification number XP_002593056). Neither has discoidin domains (fig. 3).

\section{An Unexpected Close Relative of Vertebrate Fibrinogen}

Yet another unexpected gene product related to a vertebrate clotting factor turned up in computer searches of the $C$. intestinales genome. In an earlier report [13], we had noted that a number of sequences had been identified that were homologous with the carboxyl domains of $\beta$ - 


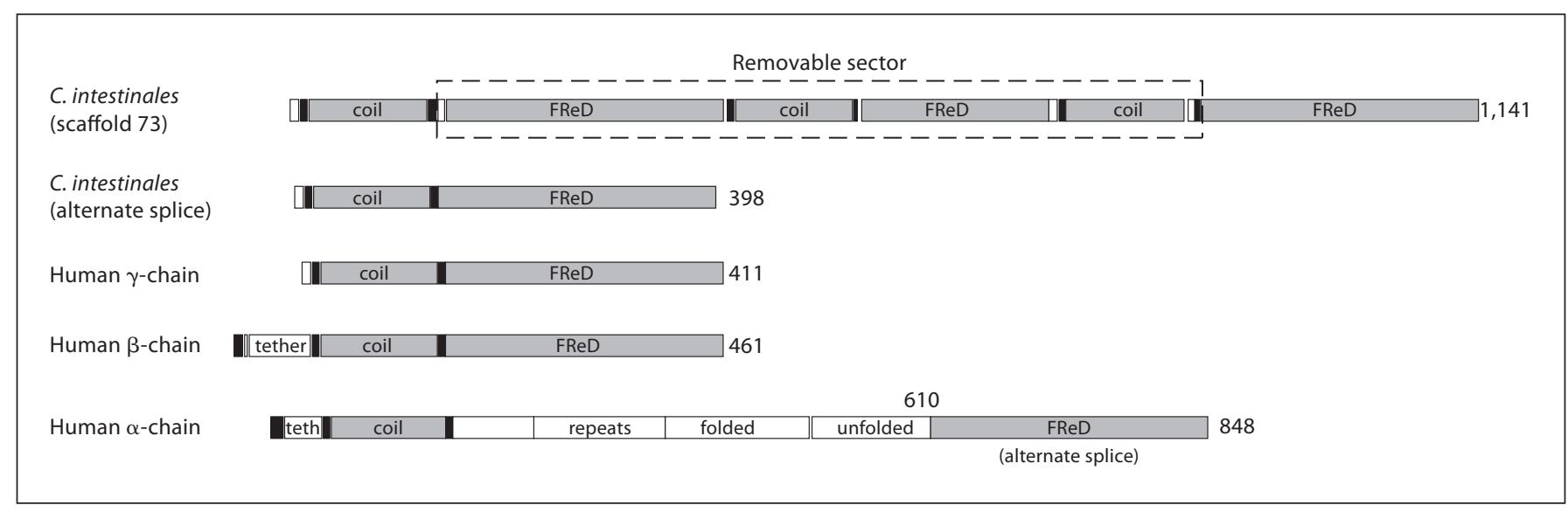

Fig. 4. Schematic depiction of a putative protein from $C$. intestinales that closely resembles the $\gamma$ - and $\beta$-chains of vertebrate fibrinogens. The full-length sequence is depicted at top and a hypothetical alternatively spliced form below it. Initially this sequence was found on scaffold 73 of the draft version of the C. intestinales genome [26]. It has since appeared in GenBank with the identification number XP_002122759.

and $\gamma$-chains of fibrinogen, domains that are widespread in animals of all kinds. We also reported that no fulllength genes were found 'with the potential for the coiled coils that are the hallmarks of fibrinogen'. We were mistaken. During the preparation of this review, I reviewed all our past searching of the $C$. intestinales genome and uncovered a putative fibrinogen-related protein that does indeed appear to have sequences that are conducive to coiled coils in the same way as genuine vertebrate fibrinogen (fig. 4).

In fact, the putative protein has numerous features characteristic of fibrinogen, including several very specific constellations of cysteine residues known as 'disulfide rings' that are crucial to holding three-stranded coiled coils in register. In the $C$. intestinales protein, two of these are separated by 110 residues; in vertebrate fibrinogen chains they are always separated by either 111 or 112 residues, something unlikely to occur by chance. Similarly, the $C$. intestinales protein may be a dimer in that it has a strategically placed cysteine residue near its amino terminus corresponding to one in the $\gamma$-chain of fibrinogen that in vertebrates forms an intermolecular disulfide bond between the two halves of the dimer.

Finally, many of the intron locations in the C. intestinales gene are the same as those in fibrinogen $\beta$ - and $\gamma$ chain genes. As such, they are compatible with an alternative splicing event that might generate a shorter protein of the same length and general arrangement as a vertebrate fibrinogen $\gamma$-chain (fig. 4). Alternatively, the middle region of the $C$. intestinales protein could either have been deleted on the lineage leading to vertebrates or inserted on the way to tunicates.

On the other hand, careful inspection of the C. intestinales sequence shows that it cannot possibly be a substrate for thrombin. There are no fibrinopeptides to be released. Nor is the protein a likely substrate for factor XIII, there being no obvious sites for cross-linking in the carboxy-terminal regions. There are also some inconveniently situated additional cysteine residues in the predicted coiled coil regions that may be incompatible with three-stranded structures.

Nonetheless, there is no doubt that the $C$. intestinales protein shares recent common ancestry with the vertebrate fibrinogen gene and is not just another 'fibrinogenrelated' protein. Finding out what its function is in tunicates should be a high priority.

\section{Allo-Recognition and Clotting Proteins}

Recently, there has been a fascinating study of allorecognition in the colonial ascidian, Botryllus schosseri, that implicated a variety of proteins related to vertebrate clotting factors [33]. Remarkably, when different colonies of this organism were brought into contact, a strong selfnonself reaction was provoked that resulted in cell clumping at the sites of contact. Taking a bold molecular biology approach, the authors prepared total RNA from the two colonies separately, as well as from differentially expressed sequence tags obtained as products of the rejec- 
tion phenomenon. When the latter were amplified by RTPCR, a large number of candidates were obtained that were implicated in the histo-incompatible process. Prominent among these were many serine proteases, as well as proteins sequentially related to fibrinogen, clotting factors V/VIII, von Willebrand factor, thrombospondin, serpins like antithrombin III and transglutaminase like factor XIII. Most of these identifications appear to be based on domains found in those vertebrate proteins and may not reflect the involvement of genuine orthologs. It is a fascinating result all the same.

\section{Amphioxus}

The amphioxus genome has also been scrutinized for relatives of vertebrate clotting factors, and given that this protochordate is more distantly related to vertebrates than tunicates, it is not surprising that the findings have been sparse. Cloning efforts have mostly resulted in proteins that have commonly shuffled domains like FreDs [34]. An exception may be the identification of a twokringle-containing protease from $B$. belcheri that has most of the hallmarks of vertebrate plasminogen [35]. Although the protein lacks the terminal PAN (plasminogen-apple-nematode) domain and three of the kringles found in all vertebrate plasminogens, the sequence of the serine protease portion strongly resembles plasminogen (45\% identical) and, when back-searched against Gen-
Bank, finds plasminogen as its best match, along with several very similar sequences from the fully sequenced B. floridae. Plasminogen may very well be a protein for which genuine orthologs occur in protochordates.

Orthologs of vertebrate complement proteins also occur in amphioxus, as has been shown by cloning studies that yielded authentic sequences for complement proteins C3 and C6 [36].

\section{Concluding Remark}

The numbers of proteins involved in vertebrate blood clotting and associated inflammatory responses has increased greatly during the course of evolution as a result of gene duplications, the main driving force leading to biological complexity. The patterns of this increase are also consistent with what is referred to as the ' $2 \mathrm{R}$ hypothesis,' the proposal that two whole genome duplications occurred during the course of vertebrate evolution, as initially suggested by S. Ohno in a 1970 monograph [37]. Current thinking places one of these events between the divergence of protochordates and the appearance of vertebrates, and the other soon after the divergence of jawless fish like the lamprey [38]. As such, whole genome doublings may have contributed significantly to the expansion of components involved in clotting and inflammation in early vertebrates.

\section{References}

1 Aird WC: Sepsis and coagulation. Crit Care Clin 2005;21:417-431.

2 Strukova S: Blood coagulation-dependent inflammation. Coagulation-dependent inflammation and inflammation-dependent thrombosis. Front Biosci 2006;11:59-80.

-3 Oehmcke S, Herwald H: Contact system activation in severe infectious diseases. J Mol Med 2010;88:121-126.

-4 Armstrong D, Jepson JB, Keele CA, Stewart JW: Pain-producing substance in human inflammatory exudates and plasma. J Physiol 1957; 135:350-370.

5 Margolis J: Activation of plasma by contact with glass: evidence for release of a common reaction which releases plasma kinin and initiates coagulation. J Physiol 1958;144:122.
6 Muller F, Mutch NJ, Schenk WA, Smith SA, Esterl L, Spronk HM, Schmidbauer S, Gahl WA, Morrissey JH, Renne T: Platelet polyphosphates are proinflammatory and procoagulant mediators in vivo. Cell 2009;139: 1143-1156.

7 Ponczec MB, Gailani D, Doolittle RF: Evolution of the contact phase of vertebrate blood coagulation. J Thromb Haemostasis 2008;6: $1-8$.

8 Delezenne C: Recherches dur la coagulation du sang chez les oiseaux. Arch Physiol Norm Path 1897;29:333-377.

$\checkmark 9$ Didisheim P, Hattori K, Lewis JH: Hematologic and coagulation studies in various animal species. J Lab Clin Med 1959;53:866875.

10 Soulier JP, Wartelle O, Menache D: Hageman Trait and PTA deficiency; the role of contact of blood with glass. Brit J Hematol 1959;5: 121-138.
11 Doolittle RF: Step-by-step evolution of vertebrate blood coagulation. Cold Spring Harbor Symp Quant Biol 2009;74:35-40.

12 Robinson AJ, Kropatkin M, Aggeler PM: Hageman factor (fXII) deficiency in marine mammals. Science 1969;166:1420-1422.

13 Jiang Y, Doolittle RF: The evolution of vertebrate blood coagulation as viewed from a comparison of puffer fish and sea squirt genomes. Proc Natl Acad Sci USA 2003;100: 7527-7532.

14 Doolittle RF, Nand J, Jiang Y: Genomic evidence for a simpler clotting scheme in jawless vertebrates. J Mol Evol 2008;66:185-196.

15 Zhou L, Li-Ling J, Huang, H, Fei M, Li Q: Phylogenetic analysis of vertebrate kininogen genes. Genomics 2008;91:10024-10028.

16 Zhou L, Liu X, Jin P, Li Q: Cloning of the kininogen gene from Lampetra japonica provides insights into its phylogeny in vertebrates. J Genet Genomics 2009;36:109-115. 
17 Conlon JM, Olson KR: Purification of a vasoactive peptide related to lysyl-bradykinin from trout plasma. FEBS Lett 1993;334:7578.

18 Bromee T, Venkatesh B, Brenner S, Postlethwait $\mathrm{JH}$, Yan YL, Larhammar D: Uneven evolutionary rates of bradykinin B1 and B2 receptors in vertebrate lineages. Gene 2006; 373:100-108.

19 Osterud B, Rapaport SI: Activation of factor IX by the reaction product of tissue factor and factor VII: additional pathway for initiating blood coagulation. Proc Natl Acad Sci USA 1977;74:5260-5264.

-20 Kimura A, Ikeo K, Nonaka M: Evolutionary origin of vertebrate blood complement and coagulation systems inferred from liver EST analysis of lamprey. Develop Comp Immunol 2008;33:77-87.

-21 Ragg H, Kumar A, Koster K, Bentele C, Wang Y, Frese M-A, Prib N, Kruger O: Multiple gains of spliceosomal introns in a superfamily of vertebrate protease inhibitor genes. BMC Evol Biol 2009;9:208-219.

22 Feng J, Yano K, Monahan-Earley R, Morgan ES, Dvorak AM, Selike FW, Aird WC: Vascular bed-specific endothelium-dependent vasomotor relaxation in the hagfish, Myxine glutinosa. Am J Physiol Regul Integr Comp Physiol 2007;293:R894.

23 Brown JA, Cobb CS, Frankling SC, Rankin JC: Activation of the newly discovered cyclostome rennin-angiotensin system in the river lamprey Lampetra fluviatilis. J Exper Biol 2005;208:223-232.
24 Libants S, Carr K, Wu H, Teeter JH, ChungDavidson YW, Zhang Z, Wilkerson C, Li W: The sea lamprey Petromyzon marinus genome reveals the early origin of several chemosensory receptor families in the vertebrate lineage. BMC Evol Biol 2009;9:180-193.

25 Endo Y, Takahashi M, Nakao M, Saiga H, Sekine $\mathrm{H}$, Matsushita M, Nonaka M, Fujita T: Two lineages of mannose-binding lectinasociated serine protease (MASP) in vertebrates. J Immunol 1998;161:4924-4930.

26 Dehal P, Satou Y, Campbell RK, et al: The draft genome of Ciona intestinales: insights into chordate and vertebrate origins. Science 2002;298:2157-2167.

27 Putnam N, Butts T, Ferrier DE, et al: The amphioxus genome and the evolution of the chordate karyotype. Nature 2008;453:10641071.

28 Rowley AF, Rhodes CP, Ratcliffe NA: Protochordate leucocytes: a review. Zoolog J Linnean Soc 1984;80:283-295.

-29 Takahashi H, Azumi K, Yokosawa H: Hemocyte aggregation in the solitary ascidian $\mathrm{Hal}$ ocynthia roretzi: plasma factors, magnesium ion, and Met-Lys-bradykinin induce the aggregation. Biol Bull 1994;186:247-253.

30 Shishekura F, Ohtake T, Tanaka K: Purification and characterization of a 39,000-Da serine proteinase from the hemolymph of a solitary ascidian, Halocynthia roretzi. Comp Biochem Physiol B Biochem Mol Bio 1997; 118:131-141.

31 Kulman JD, Harris JE, Nakazawa N, Ogasawara M, Satake M, Davie EW: Vitamin Kdependent proteins in Ciona intestinales, a basal chordate lacking a blood coagulation cascade. Proc Natl Acad Sci, USA 2006;103: 15794-15799.
32 Wang CP, Yagi K, Lin PJ, Makabe KW, Stafford DW: Identification of a gene encoding a typical $\gamma$-carboxyglutamic acid domain in the tunicate Halocynthia roretz. J Thromb Haemostasis 2002;1:118-123.

33 Oren M, Escande MI, Paz G, Fishelson Z, Rinkevich B: Urochordate histoincompatible interactions activate vertebrate-like coagulation system components. PLoS One 2008;3:e3123.

34 Fan C, Zhang S, Chao LLY: Fibrinogen-related protein from amphioxus Branchiostoma belcheri is a multivalent pattern recognition receptor with a bacteriolytic activity. $\mathrm{Mol}$ Immunol 2008;45:3338-3346.

- 35 Liu M, Zhang S: A kringle-containing protease with plasminogen-like activity in the basal chordate Branchiostoma belcheri. Biosci Reports 2009;29:385-395.

36 Suzuki MM, Satoh N, Nonaka, M: C6-lile and C3-like molecules from the cephalochrodate, amphioxus, suggest a cytolytic complement system in invertebrates. J Mol Evol 2002;54:671-679.

37 Ohno S: Evolution by Gene Duplication. New York, Springer-Verlag, 1970.

38 Escriva H, Manzon L, Youson J, Laudet V: Analysis of lamprey and hagfish genes reveals a complex history of gene duplications during early vertebrate evolution. Mol Biol Evol 2002;19:1440-1450. 